\title{
Professional Identity or Best Practices?-An Exploration of the Synergies between Professional Learning Communities and Communities of Practices
}

\author{
Daphnee H. L. Lee, Imran Shaari \\ National Institute of Education, Nanyang Technological University, Singapore \\ Email: daphnee.lee@nie.edu.sg, imran.shaari@nie.edu.sg \\ Received May $4^{\text {th }}$, 2012; revised June $10^{\text {th }}, 2012$; accepted June $20^{\text {th }}, 2012$
}

\begin{abstract}
This paper attempts to find the synergies between Professional Learning Community (PLC) and Community of Practice (CoP), with the view to enhance teacher professionalism. Based on the review of literatures, we highlight the different motivations of PLCs and CoPs, and the value-assumptions informing the two initiatives. We argue that both initiatives serve critical functions in augmenting teacher autonomy. Although conceptually distinctive, the underpinning values of the approaches to organizing teacher professional communities are complementary. Therefore, a two-prong approach is proposed. One seeds teacher professionalism through emergent best practices. The other consolidates these best practices into a coherent teacher professional identity through the introduction of structural affordances.
\end{abstract}

Keywords: Communities of Practice; Professional Learning Community; Teacher Professionalism; Professional Identity/Autonomy; Best Practices

\section{Introduction}

This paper attempts to find the synergies between Professional Learning Community (PLC) and Community of Practice $(\mathrm{CoP})$, with the view to enhance teacher professionalism. Based on the review of literatures, we highlight the different motivations of PLCs and CoPs, and the value-assumptions informing the two initiatives. We argue that both initiatives serve critical functions in augmenting teacher autonomy. Although conceptually distinctive, the underpinning values of the approaches to organizing teacher professional communities are complementary. Therefore, a two-prong approach is proposed. One seeds teacher professionalism through emergent best practices. The other consolidates these best practices into a coherent teacher professional identity through the introduction of structural affordances.

\section{Literature Review of the Conceptual Premises of PLCs and CoPs}

\section{Confluences in Practice}

The Professional Learning Community, within the education context, refers to the active engagement in professional learning, with the aim of enhancing teacher professional identity. The notion takes root in John Dewey's proposition that the resolution of recurring knowledge gaps hinges upon a continuous and cyclical process of reflection (Dewey, 1986). The PLC practitioner is, thus, one who actively acquires professional identification through reflective and collaborative dialogue with likeminded teacher professionals. The process involves participation in cycles of collaborative inquiry (DuFour, DuFour, Eaker, \& Many, 2010; Levine, 2010; Nehring \& Fitzsimons, 2011; Stoll, Bolam, McMahon, Wallace, \& Thomas, 2006; Wong, 2010), reflection (Campbell, 2005; Falk \& Drayton, 2009;
Louis \& Marks, 1998; Musanti \& Lucretia, 2010; Nehring \& Fitzsimons, 2011; Pella, 2011; Stoll et al., 2006; Vescio, Ross, \& Adams, 2007; Wiley, 2001; Wong, 2010), action research (DuFour et al., 2010; Levine, 2010; Webster-Wright, 2009) and/ or lesson studies (Foo \& Lee, 2008), for the purpose(s) of reforming pedagogy and curriculum (Harris, 2011; Little \& Veugelers, 2005), and/or transforming school/ education culture, values, vision and action (Cranston, 2011; Falk \& Drayton, 2009; Hoffman, Dahlman, \& Zierdt, 2009; Little \& Veugelers, 2005; Nehring \& Fitzsimons, 2011; Pella, 2011; Servage, 2008; Webster-Wright, 2009; Wong, 2010). Teacher identity is said to be enhanced by a corresponding enhancement of their professional capacity, which is, the ability to "achieve better results for the students they serve" (DuFour et al., 2010: p. 11).

The CoP is, according to Wenger, McDermott, and Snyder (2002), a congregation of practitioners who seek to deepen knowledge expertise (4). It is through the process of ongoing practice that members develop professionally (Lave \& Wenger, 1991). To associate practice and community, Wenger (1998) emphasizes the importance of a shared repertoire of practices that is emergent from mutual engagement in reflective dialogues. As with PLCs, the structure of CoPs are loosely defined and "members" are usually part of networks or other larger organizations. In schools, this implies that the teachers may be part of small networks (e.g. dedicated to improvements in assessment) or a large cluster of schools (e.g. groups of schools in a district) (Wenger \& Snyder, 2000).

However, the similarities between the two constructs stop there and scholars agree on how they differ (McDermott \& Archibald, 2010; Raven, 2003; Wenger \& Snyder, 2000).

\section{Divergences in Organization}

Based on the review of literatures on the key PLC attributes 
propounded by its supporters, engagement in PLC signals the commitment to embrace alternatives to traditional notions of professional learning. Departing from the preoccupation with “quick solutions and immediate results" (DuFour et al., 2010: p. 514), teachers take charge and reflect upon their daily work processes, and professional identity takes shape from this collaborative reflection. The acquisition of teacher autonomy is less daunting when like-minded professionals congregate in collaboration to this effort, rather than attempt to do so in the private practice of one's isolated classroom.

The PLC's emphasis on collaboration and reflection differentiates teacher professional learning from traditional notions of it. However, casting the exclusive focus on the two attributes conflates PLCs and CoPs (Campbell, 2005; Dooner, Mandzuk, \& Clifton, 2007; DuFour et al., 2010; Falk \& Drayton, 2009; Levine, 2010; Louis \& Marks, 1998; MOE, 2010; Musanti \& Lucretia, 2010; Nehring \& Fitzsimons, 2011; Stoll, et al., 2006; Vescio et al., 2007; Webster-Wright, 2009; Wiley, 2001; Wong, 2010), rendering them conceptually indistinguishable. As conceptual distinctions exist between the two concepts that could result in dissimilar outcomes in the way teacher capacity is to be enhanced, we deem it crucial to identify these distinctions, in view of the implications that can be drawn for teacher professional development.

PLCs and CoPs diverge in the lens they adopt towards teacher development. Although both models promise to be the counter-cultural force for enhancing teacher efficacy, the CoP appears more promising in performing this function than its counterpart in question. If an initiative is to remain true to the profession of "teachers taking charge", the organic approach taken to form communities appears much more attractive. (Falk \& Drayton, 2009) In contrast, PLC implementations tend to be predominated by top-down initiatives targeted at shaping teacher identities. The empirical reality of how the two initiatives unfold on the ground makes sense in the light of the different priorities that take precedence between the two models.

The more practice-based approach of CoPs makes learning more immediate to the learner (Aguilar \& Krasny, 2011; Bouchamma \& Michaud, 2010; Chambers \& Armour, 2011; Dooner et al., 2007; Falk \& Drayton, 2009; Levine, 2010; Lewis, Koston, Quartley, \& Adsit, 2011; Musanti \& Lucretia, 2010; Parker, Patton, Madden, \& Sinclair, 2010; Thang, Hall, Murugaiah, \& Hazita, 2011). Bottom-up initiatives may be more attractive to the ground practitioner than abstract notions of professional identity acquisition, which requires a vantage point from the top. It may also be tedious to engage in distant associations of "teacher learning for student outcomes" (Louis \& Marks, 1998; MOE, 2010; Nehring \& Fitzsimons, 2011; Stoll et al., 2006; Vescio et al., 2007; Wiley, 2001), or high-brow notions of an emergent value-system from the convergence of value-identities (Levine, 2010).

Nevertheless, being less attractive does not correspondingly mean being less vital. The PLC serves crucial functions in enacting change more effectively than CoPs under specific contexts. In environments that are already highly institutionalized, such as the school environment, change initiatives may be ineffective when solely employing CoP approaches. As Levine cautions, the trajectory of practitioners advancing to core expertise from the periphery may or may not happen with CoPs (2010).

\section{Implications}

Conceptually, there appears to be an irreconcilable dichotomy between PLCs and CoPs. When operating in reality, however, the differences are much less defined, and may even be complementary. That is, communities operating under the moniker of PLCs may in practice possess strong elements of CoP, and vice versa. For instance, while embarking upon the onerous process of professional identity formation, PLC practitioners may be concurrently engaged in sharing best practices more immediate to the challenges of classroom management. Likewise, $\mathrm{CoP}$ practitioners may come to adopt more defined forms of professional identification when membership criteria take shape. Viewed from the vantage point, there is much empirical convergence between the two constructs, despite their theoretical divergences. While some applaud the co-existence of parallel movements dedicated to teacher professional development, others question if duplicate movements unnecessarily overload the already time-challenged teachers. Our take tends towards the former view. Indeed, much controversy remains over the differentiated conceptual grounds and empirical fuzziness of the two. Although these debates address important issues, our concern tends towards how the ultimate end embodied by these communities, nevertheless, serve the critical function of teacher professional enhancement. Both movements entail the embracement of a learning culture that is no longer about passive transmission of knowledge, acquired through an active cocreation process, which will empower teachers with the capacity to exercise professional autonomy. While it is important to not conflate the two to ensure the best of both elements are integrated in professional development, the view that teachers are unable to apply both concepts into practice is overly mechanistic.

The CoP's focus on unstructured practice forms an important basis for exploratory inquiry and authentic learning. Where teachers possess limited capacity for systematic inquiry, novice learning by simulation (i.e. "legitimate peripheral participation") CoP-style provides the unstructured learning with the space for exploration (Lambsom, 2010). The loose community relationships allows for a dynamic bottom-up learning initiative that adapts with the learning priorities of the time. However, when left as it is, a community formed on the basis of the CoP model can take a long time for an emergent organization principle, if it emerges at all. CoPs may lose its capacity to generate emergent insights if its communities are obligated to devolve systematic capacities. PLCs are able to complement CoPs with the capacity for more sustained organization efforts. The development of conceptual expertise requires concerted action steered beyond immediate learning priorities. It requires the dissemination of common epistemologies that reflects guiding values of an esteemed profession. While the PLC's preoccupation with structure and identity puts limits on possibilities, it also consolidates a common lingo that characterizes the professional identity of a discipline. PLC practitioners, as members of a profession, are intuitively oriented as professionals based on the shared identification with the values propounded. It will be all the better, if professional values are shaped by the everyday practices derived from CoPs. Optimal learning requires conditions that provides for both systematic inquiry and organically emergent insights. This need for system-emergent capacity can be provided for if teacher professionals subscribe to both CoPs and/or PLCs. 
Summarily, a dialectical engagement with system (PLC) and emergence ( $\mathrm{CoP})$ is beneficial to sustainable teacher professional development. As a further elaboration of the global-local duality in Wenger's (1998) theorizations of CoP, Bertram charts the trajectory of professional communities with the analogy of "building an airplane in the air" (Bruce, 2009). We extend upon this proposition that while the sky is the limit when it comes to scaffolding for innovative practices, building an airplane that flies requires innovation to eventually take institutionalized forms. Both community models can be present in schools concurrently and contingently, depending on individual school requirements. For instance, if School A is just beginning to experiment with devolving from traditional schooling methods, a radical departure into overly exploratory approaches may create strong teacher resistance. The school may opt for PLCstyle communities predominantly, while making some provisions for CoP-inspired groups to emerge. School B may be characterized by weak leadership, which necessitates teachers to play a more proactive role at exploring their own learning direction within poorly defined professional boundaries. Under this circumstance, the adoption of CoP predominant communities, coupled with some initiative for identity-shaping PLCs may be a prudent option. School C may have enjoyed successful track records of compiling innovative professional practices from current CoP communities. The school may chart a trajectory of surfacing more PLC-like com-munities, so that looselylinked practices can be solidified into translatable practices that can be scaled system-wide based on consistent core values. This shift may take place with some groups embarking upon the PLC trajectory, while others remain committed to exploratory endeavors in CoPs. This view of continuous dialectical engagement can be likened to a (mid)top-down consolidation of emergent bottom-up phenomena (i.e. professionalization), for the enablement of sustainable innovation in professional learning (McDermott \& Archibald, 2010).

\section{Conclusion}

PLCs consolidate teacher identifications into professional identities, organizing and connecting teachers as a professional community. CoPs engage teachers as professional practitioners, with amorphous community obligations to allow for the emergence of professional innovation. With regard to teacher professionalization and professional development, the two share a symbiotic relationship. The distinctive models converge in the ultimate goal of enhancing teacher professional standing. Though not necessarily mutually exclusive, the means to enhancing teacher professional standing differ, and hence, the end results. If professional community organization obligates the selection of one form over another, the end goal may still be partially achieved, but not at the optimal capacity. Teachers are lesser professional members if their craft is not constantly reviewed for rejuvenation. Likewise, teachers are also lesser professional practitioners if their craft is unguided by a common identity. The trajectory of teacher professional development lies in seeding, growth, integration, dissemination, consolidation, institutionalization, and renewal. When integrated, CoPs and PLCs offer the sustainable means to this end.

\section{REFERENCES}

Aguilar, O. M., \& Krasny, M. E. (2011). Using the communities of practice framework to examine an after-school environmental education program for Hispanic youth. Environmental Education Research, 17, 217-233. doi:10.1080/13504622.2010.531248

Bruce, B. C. (2009). "Building an airplane in the air": The life of the inquiry group. In J. K. Falk, \& B. Drayton (Eds.), Creating and sustaining online professional learning communities (pp. 47-67). New York: Teachers College Press.

Bouchamma, Y., \& Michaud, C. (2010). Communities of practice with teaching supervisors: A discussion of community members' experiences. Journal of Educational Change, 12, 403-420. doi:10.1007/s10833-010-9141-y

Campbell, E. (2005). Challenges in fostering ethical knowledge as professionalism within schools as teaching communities. Journal of Educational Change, 6, 207-226. doi:10.1007/s10833-005-7107-2

Chambers, F. C., \& Armour, K. M. (2011). Do as we do and not as we say: teacher educators supporting student teachers to learn on teaching practice. Sport, Education and Society, 16, 527-544. doi:10.1080/13573322.2011.589648

Cranston, J. (2011). Relational trust: The glue that binds a professional learning community. Alberta Journal of Educational Research, 57, 59-72.

Dewey, J. (1986). Logic: The theory of inquiry. In J. A. Boydston (Ed.), John Dewey: The later works (Vol. 12, pp. 1-506). Carbondale: Southern Illinois.

Dooner, A.-M., Mandzuk, D., \& Clifton, R. A. (2007). Stages of collaboration and the realities of professional learning communities. Teaching and Teacher Education, 24, 564-574. doi:10.1016/j.tate.2007.09.009

DuFour, R., DuFour, R., Eaker, R., \& Many, T. (2010). Learning by doing: A handbook for professional learning communities at work (2nd ed.). Indiana: Solution Tree Press.

Falk, J. K., \& Drayton, B. (Eds.). (2009). Creating and sustaining online professional learning communities. New York: Teachers College Press.

Foo, K. F., \& Lee, H. P. (2008). Building a professional learning community in east zone through lesson study. The APERA Conference: Educational Research for Innovation \& Quality in Education: Policy \& Pedagogical Engagements across Contexts, Singapore, 26-28 November 2008.

Harris, A. (2011). Reforming systems: Realizing the fourth way. Journal of Educational Change, 12, 159-171. doi:10.1007/s10833-011-9156-Z

Hoffman, P., Dahlman, A., \& Zierdt, G. (2009). Professional learning communities in partnership: A 3-year journey of action and advocacy to bridge the achievement gap. School-University Partnerships, 3, 28-42.

Lave, J., \& Wenger, E. (1991). Situated learning: Legitimate peripheral participation. New York: Cambridge University Press. doi:10.1017/CBO9780511815355

Lave, J., \& Wenger, E. (1998). Communities of practice: Learning, meaning, and identity. Cambridge: Cambridge University Press.

Levine, T. H. (2010). Tools for the study and design of collaborative teacher learning: The affordances of different conceptions of teacher community and activity theory. Teacher Education Quarterly, 37, 109-130.

Lewis, L. A., Koston, Z., Quartley, M., \& Adsit, J. (2011). Virtual communities of practice: Bridging research and practice using web 2.0. Journal of Educational Technology Systems, 39, 155-161. doi:10.2190/ET.39.2.e

Little, J. W., \& Veugelers, W. (2005). Big change question: Professional learning and school-network ties: Prospects for school improvement. Journal of Educational Change, 6, 277-291. doi:10.1007/s10833-005-8254-1

Louis, K. S., \& Marks, H. M. (1998). Does professional community affect the classroom? Teachers' work and student experiences in restructuring schools. American Journal of Education, 106, 532-575. $\underline{\text { doi: } 10.1086 / 444197}$

McDermott, R., \& Archibald, D. (2010). Harnessing your staff's informal networks. Harvard Business Review: The Magazine. URL. http://hbr.org/2010/03/harnessing-your-staffs-informal-networks/ar/3 MOE, (2010). Schools as professional learning communities (2nd ed.). 


\section{H. L. LEE, I. SHAARI}

Singapore: MOE.

Musanti, S. I., \& Lucretia, P. (2010). Collaboration and teacher development: Unpacking resistance, constructing knowledge, and navigating identities. Teacher Education Quarterly, 37, 73-89.

Nehring, J., \& Fitzsimons, G. (2011). The professional learning community as subversive activity: Countering the culture of conventional schooling. Professional Development in Education, 37, 513-535. doi:10.1080/19415257.2010.536072

Parker, M., Patton, K., Madden, M., \& Sinclair, C. (2010). From committee to community: The development and maintenance of a community of practice. Journal of Teaching in Physical Education, 29, 337-357.

Pella, S. (2011). A situative perspective on developing writing pedagogy in a teacher professional learning community. Teacher Education Quarterly, 38, 107-125.

Raven, A. (2003). Team or community of practice alighning tasks, structures and technologies. In C. B. Gibson, \& S. G. Cohen (Eds.), Virtual teams that work (pp. 292-306). San Francisco: Wiley \& Sons.

Servage, L. (2008). Critical transformative practices in professional learning communities. Teacher Education Quarterly, 35, 63-77.

Stoll, L., Bolam, R., McMahon, A., Wallace, M., \& Thomas, S. (2006). Professional learning communities: A review of the literature. Journal of Educational Change, 7, 221-258.

doi:10.1007/s10833-006-0001-8
Thang, S. M., Hall, C., Murugaiah, P., \& Hazita, A. (2011). Creating and maintaining online communities of practice in Malaysian smart schools: Challenging realities. Educational Action Research, 19, 87105. doi:10.1080/09650792.2011.547724

Vescio, V., Ross, D., \& Adams, A. (2007). A review of research on the impact of professional learning communities on teaching practice and student learning. Teaching and Teacher Education, 24, 80-91. doi:10.1016/j.tate.2007.01.004

Webster-Wright, A. (2009). Reframing professional development through understanding authentic professional learning. Review of Educational Research, 79, 702-739. doi:10.3102/0034654308330970

Wenger, E., McDermott, R., \& Snyder, W. M. (2002). Cultivating communities of practice: A guide to managing knowledge. Boston: Harvard Business School Press.

Wenger, E., \& Snyder, W. M. (2000). Communities of practice: The organizational frontier. Harvard Business Review, 78, 139-145.

Wiley, S. D. (2001). Contextual effects on student achievement: School leadership and professional community. Journal of Educational Change, 2, 1-33. doi:10.1023/A:1011505709050

Wong, J. L. N. (2010). What makes a professional learning community possible? A case study of a Mathematics department in a junior secondary school of China. Asia Pacific Education Review, 11, 131-139. doi:10.1007/s12564-010-9080-6 